\title{
SEJARAH HADITS MAWDU’ DALAM MUSTALAHUL HADITS
}

\author{
Abdullah \\ abdullahmasud53@gmail.com \\ STAI Taruna Surabya
}

\begin{abstract}
Abstrak : Para ulama' berbeda pendapat tentang kapan mulai terjadinya pemalsuan hadis, orang telah memalsukan berbagai hadis dengan motif dan tujuan yang berbedabeda, Terlebih untuk kepentingan-kepentingan tertentu orang bisa dan berani untuk membuat hadis palsu. Pengertian hadis secara istilah adalah Hadis yang disandarkan kepada rasulullah SAW Secara dibuat-buat dan dusta, padahal beliau tidak mengatakan berbuat ataupun menetapkannya. Mempergunakan hadis maudu' itu batal, dan haram meriwayatkannya kecuali terpaksa atau mengerjakan hadis itu kepada ahli ilmu pengetahuan untuk diteliti. Berdasarkan data sejarah yang ada, pemalsuan hadis tidak hanya dilakukan oleh orang-orang islam tetapi juga dilakukan oleh orang-orang non islam dengan berbagai macam motif dan kepentingan anatara lain Pertentangan politik, usaha kaum zindik, fanatic terhadap bangsa dan suku, mempengaruhi kaum awam dan lain sebagainya.
\end{abstract}

Kata Kunci: Hadis, Maudu'

\section{PENDAHULUAN}

Masalah hadits maudhu berawal dari pertentangan politik yang terjadi pada masa khalifah Ali Bin Abi Thalib yang berujung pada pembuatan hadits-hadits palsu yang tujuannya adalah untuk mengalahkan lawan dan mempengaruhi orangorang tertentu. Akibat perpecahan politik ini, hampir setiap golongan membuat hadits maudhu untuk memperkuat golongannya masing-masing.

Melihat kenyataan yang ada, bahwa dengan motif dan tujuan yang berbedabeda, orang telah memalsukan berbagai hadis. Terlebih untuk kepentingankepentingan tertentu orang bisa dan berani untuk membuat hadis palsu.

Semua ahli teologi muslim sepakat mengenai fakta bahwa perekayasaan hadis secara berangsur-angsur semakin kerap sejak pertengahan abad pertama hijriah, sampai penulis-penulis seperti bukhori, muslim, dan yang lainnya menyusun kitab himpunan hadis mereka yang hampir tanpa cacat. Dengan berbuat demikian mereka memberikan kepada literature hadis bentuk sahihnya yang pasti. ${ }^{1}$

\footnotetext{
${ }^{1}$ GHA. Juynball, Kontroversi hadis di mesir (1890 -1960), penerbit Mizan, bandung , 1999, Hal. 146.
} 
Para ulama' berbeda pendapat tentang kapan mulai terjadinya pemalsuan hadis. Antara lain :

1. Menurut Ahmad amin, bahwa hadis maudu' telah terjadi pada masa rasulullah SAW masih hidup. Alasan yang dijadikan argumentasi adalah sabda rasulullah SAW.

Dari Anas bin Malik radhiyallahu'anhu, Rasulullah shallallahu 'alaihi wa sallam bersabda, "Barangsiapa yang sengaja berdusta atas namaku maka hendaknya dia mengambil tempat duduknya di neraka." (HR. Bukhari, dan Muslim. $^{2}$

Dengan dikeluarkanya sabda tersebut, menurut Ahmad Amin Rosulullah SAW mengira telah ada pihak-pihak yang ingin berbuat bohong kepada dirinya. Oleh karena itu hadis tersebut merupakan respon terhadap fenomena yang ada saat itu, yang berarti menggambarkan bahwa kemungkinan besar pada zaman rasulullah telah terjadi pemalsuan hadis. Sehingga rasul mengancam kepada para pihak yang membuat hadis palsu.

2. Shalahuddin Ad Dhabi mengatakan bahwa pemalsuan hadis berkenaan dengan permasalahan keduniaan telah terjadi pada masa rasulullah. Alasan yang dikemukakan adalah hadis riwayat at Thahawi (w.321 H/933 M) dan At Thabrani (w.360 H/971 M). dalam kedua hadis tersebut dinyatakan bahwa pada masa nabi ada seseorang telah membuat berita bohong mengatasnamakan Nabi. Orang itu mengaku telah diberi wewenang nabi untuk menyelesaikan suatu masalah disutau kelompok masyarakat disekitar madinah kemudian seseorang itu melamar seorang gadis dari masyarakat tersebut, tetapi lamaran itu ditolak. Masyarakat tersebut lalu mengirim utusan kepada nabi untuk mengkonfirmasikan berita utusan tersebut. Ternyata nabi tidak pernah menyuruh seseorang yang mengatasnamakan beliau itu. Nabi lalu menyuruh sahabatnya untuk membunuh orang yang bersangkutan, seraya berpesan, apabila ternyata orang yang bersangkutan telah meningal dunia, maka jasad orangitu agar

\footnotetext{
${ }^{2}$ Hadis ini mutawatir yang diriwayatkan lebih dari 60 sahabat, bahkan ada yang mengatakan lebih dari 200 sahabat.
} 
dibakar. Dalam kedua hadis baik yang diriwayatkan Thahawy ataupun thabrani ternyata sanadnya lemah. Karena itu riwayat tersebut tidak bias dijadikan dalil. ${ }^{3}$

3. Menurut jumhurul muhaddisin bahwa pemalsuan hadis itu terjadi pada masa kekhalifahan Ali bin Abi Thalib, ${ }^{4}$ mereka beralasan bahwa keadaan hadis sejak zaman nabi sehingga sebelum terjadinya pertentangan antar Ali bin Abi Thalib dengan muawiyah bin abi sofyan (w. $60 \mathrm{H} / 680 \mathrm{M}$ ) masih terhindar dari pemalsuan-pemalsuan. Zaman nabi jelas tidak mungkin terjadi pemalsuan hadis, sedangkan pada masa kekhalifahan Abu baker as Shidiq, Umar bin Khatab dan Usman bin Affan belum terjadi pemalsuan hadis. Hal ini dapat dibuktikan betapa gigih, hati-hati dan waspada mereka terhadap hadis. Sebagai bukti bahwa Abu bakar dengankehati-hatiannya pernah membakar catatan-catatan hadis miliknya. Siti aisyah putrid beliau menyatakan bahwa ayahnya telah membakar catatan sekitar lima ratus hadis. Karena beliau khawatir salah salah dalam meriwayatkan hadis. Umar bin khatab juga demikian. Abu Huroiraoh menyatakan, sekiranya dia banyak meriwayatkan hadis pada zaman Umar niscya dia akan dicambuk oleh Umar. Dan Usman bin affan juga memiliki sikap yang sama dengan khalifah sebelumnya. Sedangkan masa Ali bin abi thalib ini sangat berbeda karena dimasa itu terjadi pertentangan antara Ali dan muawiyah yang masingmasing berusaha saling mengalahkan lawannya. Salah satu caranya adalah dengan membuat hadis palsu. ${ }^{5}$

\section{PENGERTIAN HADIS MAUDHU'}

Al Maudhu' adalah isim maf'ul dari wadha-a, ya dha-u wadh-an, yang mempunyai arti $\mathrm{Al}$ isqath (meletakkan atau menyimpan), ${ }^{6}$ al ikhtira' wal ikhtilaq (mengada-ada atau membuat-buat) dan al tarku (ditinggal).

Sedangkan pengertian hadis maudu' menurut istilah adalah :

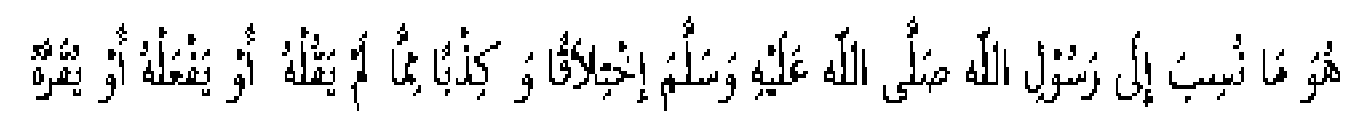

\footnotetext{
${ }^{3}$ Suhdi ismail, kaidah keshahihan hadis, telah kritis dan tinjaun dengan pendekatan ilmu sejarah, Jakarta, Bulan Bintang, 1988, hal. 92-93

${ }^{4}$ Ajjaj Al Khatib, Ushulul Hadis, Ulumuhu wa musthalahuhu, Dar Al fikr, Beirut, 1981. cet ke 4 . hlm. 416

${ }^{5}$ Ajjaj Al Khatib. Op. cit. hal. 418-420

${ }^{6}$ Drs. Munzier suprapto. M. A, dan Drs. Utang Ranuwijaya, Ilmu Hadits, raja grapindo persada, Jakarta, 1993, h, 191
} 
"Hadis yang disandarkan kepada rasulullah SAW. Secara dibuat-buat dan dusta, padahal beliau tidak mengatakan berbuat ataupun menetapkannya"?

Sebagian mereka mengatakan bahwa yang dimaksud dengan hadis maudhu' ialah :

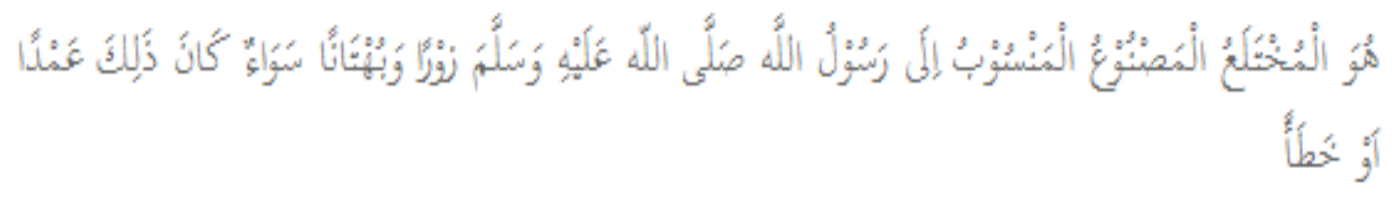

"Hadis yang dibuat-buat oleh seseorang (pendusta) yang ciptaan ini dinisbatkan kepada rasulullah secara paksa dan dusta, baik sengaja maupun tidak."

Jadi hadis maudhu' adalah bukan hadis yang bersumber dari rasul atau dengan kata lain bukan hadis rasul, akan tetapi suatu perkataan atau perbuatan seseorang atau pihak-pihak tertentu dengan sutau alasan kemudian dinisbatkan kepada rasul. ${ }^{9}$

\section{HUKUM DAN LATAR BELAKANG TIMBULNYA HADIS MAUDHU'}

Umat Islam telah sepakat bahwa hukum membuat dan meriwayatkan hadits maudhu' dengan sengaja adalah haram secara mutkaq, bagi mereka yang sudah mengetahui hadits itu palsu. Adapun bagi mereka yang meriwayatkan dengan tujuan memberi tahu kepada orang bahwa hadits ini adalah palsu (menerangkan sesudah meriwayatkan atau membacanya), tidak ada dosa atasnya.

Mereka yang tidak tahu sama sekali kemudian meriwayatkannya atau mereka mengamalkan makna hadits tersebut karena tidak tahu, tidak ada dosa atasnya. Akan tetapi, sesudah mendapatkan penjelasan bahwa riwayat atau hadits yang dia ceritakan atau amalkan itu adalah hadits palsu, hendaklah segera dia tinggalkannya, kalau tetap dia amalkan, sedangkan dari jalan atau sanad lain tidak ada sama sekali, hukumnya tidak boleh

Sehingga hukum hadis maudhu' itu adalah batal, haram meriwayatkannya, kecuali terpaksa atau mengerjakan hadis itu kepada ahli ilmu pengetahuan. ${ }^{10}$ Dan

\footnotetext{
${ }^{7}$ Subhi as-Salih, 'ulum al-hadits wa Mustalahahuh, Dar al-ilm al-malayin, 1997, h, 263

${ }^{8}$ Mahmud abu rayah, adlwa' 'ala sunnah al muhammadiyah, Dar al-Ma'arif, Mekah, h.119

${ }^{9}$ Munzier suparta, Ilmu Hadis, Rajawali Perss. Jakarta, 2001, hal. 176

${ }^{10}$ Sayid Muhammad bin alwi almaliki, Kaidah-kaidah dasar ilmu hadits, Apollo, Surabaya, tt, hal. 46
} 
berdasarkan data sejarah yang ada, pemalsuan hadis tidak hanya dilakukan oleh orangorang islam tetapi juga dilakukan oleh orang-orang non islam.

Masuknya secara masal penganut agama lain kedalam islam, yang merupakan dari keberhasilan dakwah islamiyah keseluruh pelosok dunia, secara tidak langsung menjadi faktor munculnya hadits-hadits palsu. Kita tidak bisa menafikan bahwa masuknya mereka keislam,disamping ada yang benar-benar ikhlas, ada juga segolongan mereka yang mennganut agama islam hanya karena terpaksa tnduk pada kekuasaan islam pada waktu itu. Golongan ini kita kenal dengan kaum Munafik. ${ }^{11}$

Ada beberapa motif yang mendorong mereka membuat hadis palsu, antara lain :

1. Pertentangan politik

Perpecahan umat islam diakibatkan oleh politik terjadi pada masa khalifah Ali bin Abi Thalib, dan ini akibatnya besar sekali pada perpecahan golongan dan kemunculan hadis palsu.demi untuk mengalahkan kelompok lain mereka rela untuk mebuat dalil-dalil palsu. yang pertama yang paling banyak membuat hadits Maudhu' adalah golongan Syiah dan Rafidhah. ${ }^{12}$

Diantara hadits-hadits yang dibuat golongan syiah adalah:

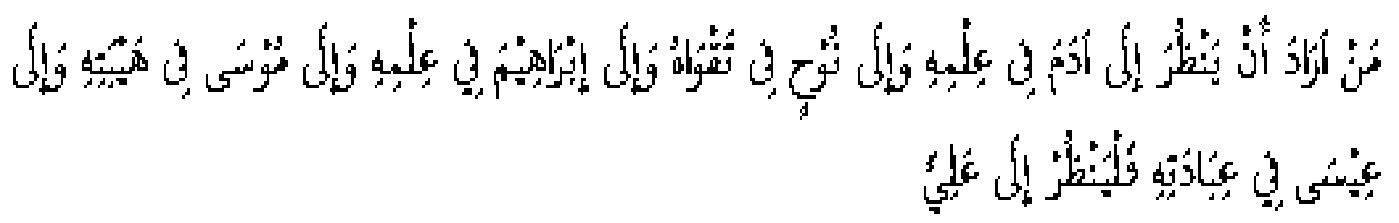

" Barang siapa tyang ingin melihat Adam tentang ketinggian ilmunya, ingin melihat Nuh tentang ketakwaannya, ingin melihat Ibrahim tentang kebaikan hatinya, ingin melihat Musa tentang kehebatannya, ingin melihat isa tentang ibadahnya, hendaklah melihat Ali.

2. Usaha kaum zindiq

Kaum zindiq merupakan golongan kaum yang sangat membenci Islam, baik islam sebagai agama atau sebagadai dasar Negara/pemerintahan. Dan mereka dapat melampiaskan kebencian mereka melalui konfrontasi dan pemalsuan baik

\footnotetext{
${ }^{11}$ Abdul Fatah Abu Ghuddah, lamhat Min Tarikh As-Sunnah wa Ulum Al-Hadits, hlm 41

12 M. Hasbi Ash-Shiddiqy. Sejarah dan Pengantar Ilmu Hadits, jakarta: Bulan Bintang, 1987. Hlm 246
} 
alquran maupun hadis. Hammad bin zaid mengatakan "hadis yang dibuat kaum zindiq ini berjumlah 12.000 hadis. $^{13}$

3. Fanatic terhadap bangsa, suku, negeri, bahasa dan pimpinan mereka membuat hadis palsu karena didorong oleh sikap ego dan fanatic buta serta ingin menonjolkan seseorang, bangsa, kelompok atau yang lain. Golongan yang fanatic terhadap madzab abu hanifah pernah memuat hadis palsu "dikemudian hari akan ada seorang umatku yang bernama abu hanifah bin nu'man, ia ibarat obor bagi umatku."

4. Mempengaruhi kaum awam dengan kisah dan nasihat mereka membuat hadis palsu dengan tujuan agar mendpatkan simpatik dari para pendengarnya dan agar mereka kagum melihat kemampuannya. Hadis yang mereka katakana terlalu berlebihan dan tidak masuk akal.

5. Perselisihan Madzab Dan Ilmu Kalam munculnya hadis palsu dalam masalah fiqh dan ilmu kalam ini brasal dari para pengikut madzab, mereka berani melakukan pemalsuan hadis karena didorong sifat fanatic dan inging menguatkan madzabnyamasing-masing. ${ }^{14}$

6. Membangkitkan gairah beribadah, tanpa mengerti apa yang dilakukan banyak diantara ulama' yang membuat hadis palsu dengan tujuan mereka bisa lebih dekat dengan Allah SWT, serta menjunjung tinggi agamanya. Nuh bin abi maryam telah membuat hadis berkenaan dengan fadilah membaca surat-surat tertentu dalam al quran.

7. Menjilat penguasa

ada juga yang membuat hadis palsu dengan tujuan agar diberi hadiah atau simpatik dari pimpinan, seperti ghiyas bin ibrahim merupakan tokoh yang banyak ditulis sebagai pemalsu hadis tentang perlombaan.

Dari beberapa motif membuat hadis palsu diatas, kiranya dapat dikelompokkan menjadi empat yakni : $:^{15}$

a. dengan kesengajaan merusak agama

\footnotetext{
${ }^{13}$ Mahmud Al Thahan, taisir musthalah hadis, Dar alquranul karim, Beirut, 1981, hlm. 70.

${ }^{14}$ Ajjaj al khatib, op.cit, hal. 141

15 Jalal Al Din Abd. Rahman bin Abi Bakar Al Suyuthi, Al Laily al mausu'ah fi hadis al maudhu'at, almaktabah al islamiyah, juz II, mesir, tt, hal. 276
} 
b. tidak sengaja merusak agama

c. dengan keyakinan bahwa membuat hadis palsu diperbolehkan

d. dirinya tidak tahu jika dirinya membuat hadis palsu

\section{CIRI-CIRI HADIS MAUDU,}

Para ulama'membuat kaidah-kaidah yang menjadi dasar dalam menetapkan hadis-hadis maudu'. Para ulama' telah menetapkan tanda-tanda atau ciri-ciri yang harus diperhatikan dengan seksama agar dapat membedakan mana hadis maudu' dan bukan maudu'. Ciri-ciri itu sebagai berikut $:^{16}$

a. Ciri-ciri yang terdapat pada sanad

1. pengakuan dari pembuat hadis maudu' Maisaroh ibnu Abi Rabbih Al Farisi mengaku bahwa ia telah membuat hadis maudu' tentang keutamaan keutamaan Al quran, beliau juga mengaku telah memaudhu'kan 70 hadis tentang keutamaan Ali ra.

2. kenyataan sejarah bahwa perowi itu tidak bertemu / tidak sezaman dengan orang yang dikatakn gurunya. Misalnya, ma'mun ibnu ahmad al harawi mengaku mendengar hadis dari hisyam ibnu hammer al hafid ibnu hibban menanyakan, “kapan kamu (ma'mun) dating ke negeri syam”, ma'mun menjawab tahun 250 H. ibnu hibban mengatakan bahwa hisyam ibnu ammar itu meninggal pada tahun 245 H. ma'mun menjawab lagi, "itu hisyam ibnu amaar yang lain.”

3. keadaan perowi itu sendiri terkenal dengan kedustaannya.

b. Ciri-ciri yang terdapat pada matan

1. berlawanan dengan pendapat akal

2. berlawanan dengan $\mathrm{Al}$ quran

3. berlawanan dengan sunnah atau hadis mutawatir

4. berlawanan dengan ijma'

\section{PENUTUP}

Para ulama' berbeda pendapat tentang kapan mulai terjadinya pemalsuan hadis, orang telah memalsukan berbagai hadis dengan motif dan tujuan yang berbeda-beda,

\footnotetext{
${ }^{16}$ Musthafa zahri, kunci memahami musthalahul hadis, bina ilmu, Surabaya, 1995. hal. 83-85
} 
Terlebih untuk kepentingan-kepentingan tertentu orang bisa dan berani untuk membuat hadis palsu.

Pengertian hadis secara istilah adalah Hadis yang disandarkan kepada rasulullah SAW Secara dibuat-buat dan dusta, padahal beliau tidak mengatakan berbuat ataupun menetapkannya. Mempergunakan hadis maudu' itu batal, dan haram meriwayatkannya kecuali terpaksa atau mengerjakan hadis itu kepada ahli ilmu pengetahuan untuk diteliti.

Berdasarkan data sejarah yang ada, pemalsuan hadis tidak hanya dilakukan oleh orang-orang islam tetapi juga dilakukan oleh orang-orang non islam dengan berbagai macam motif dan kepentingan antara lain Pertentangan politik, usaha kaum zindik, fanatic terhadap bangsa dan suku, mempengaruhi kaum awam dan lain sebagainya 


\section{DAFTAR PUSTAKA}

Ajjaj Al Khatib, Ushulul Hadis, Ulumuhu wa musthalahuhu, Dar Al fikr, Beirut, 1981. cet ke 4 .

Abdul Fatah Abu Ghuddah, lamhat Min Tarikh As-Sunnah wa Ulum Al-Hadits, tt.

GHA. Juynball, Kontroversi hadis di mesir (1890 -1960), penerbit Mizan, bandung, 1999 ,

Jalal Al Din Abd. Rahman bin Abi Bakar Al Suyuthi, Al Laily al mausu'ah fi hadis al maudhu'at, almaktabah al islamiyah, juz II, mesir, tt,

Munzier suparta, Ilmu Hadis, Rajawali Perss. Jakarta, 2001

Mahmud Al Thahan, TaisirMmusthalah Hadis, Dar alquranul karim, Beirut, 1981

Musthafa zahri, Kunci Memahami Musthalahul Hadis, bina ilmu, Surabaya, 1995.

Mahmud abu rayah, adlwa' 'ala sunnah al muhammadiyah, Dar al-Ma'arif, Mekah. Tt.

M. Hasbi Ash-Shiddiqy. Sejarah dan Pengantar Ilmu Hadits, jakarta: Bulan Bintang, 1987

Suhdi ismail, Kaidah Keshahihan Hadis, telah kritis dan tinjaun dengan pendekatan ilmu sejarah, Jakarta, Bulan Bintang, 1988

Sayid Muhammad bin alwi almaliki, Kaidah-kaidah Dasar Ilmu Hadits, Apollo , Surabaya, tt.

Subhi as-Salih, 'ulum al-hadits wa Mustalahahuh, Dar al-ilm al-malayin, 1997 